\title{
AC 2009-2427: IMPACT OF THE NNRNE PROGRAM ON OCEAN ENGINEERING EDUCATION
}

\section{Manhar Dhanak, Florida Atlantic University}

Manhar Dhanak is the Department Chair and Director of SeaTech in the Department of Ocean Engineering at Florida Atlantic University.

Ronald Yeung, University of California, Berkeley

Ronald W. Yeung is Professor in the Ocean Engineering Graduate Group at the University of California, Berkeley

\section{Spyros Kinnas, University of Texas, Austin}

Spyros Kinnas is Professor in the Department of Civil and Environmental Engineering at the University of Texas, Austin. 


\title{
Impact of the NNRNE program on ocean engineering education
}

\begin{abstract}
National Naval Responsibility for Naval Engineers (NNRNE) program was established by the Office of Naval Research in 2001 to help ensure the future US capability to develop creative and innovative ship designers and designs to effectively meet defense needs and commercial market opportunities. It was also recognized that the universities need to sustain an adequate research expertise, through working on long-term problems of importance to the Navy, so that an adequate pipeline of new researchers, engineers, and faculty exists to meet these anticipated future needs and opportunities. The program led to the formation of several university consortia for participation in the program.
\end{abstract}

The focus of the Florida Atlantic University NNRNE Consortium was chosen to be hull design and shipboard automation for future 'mission effective' Navy support ships that would be categorized as fast, responsive and automated. Principal thrust of the program has been education and training of students who will make up the next generation of ocean engineers and foster the development of novel uninhibited ideas. Over the duration of the program, ship systems specific to development of the SeaBasing concept and associated technologies were considered. The emphasized areas have been (1) seakeeping, (2) dynamic stability, (3) drag reduction and propulsion, and (4) shipboard automation and control. The goal of the program is the development of conceptual designs of mission effective ships and onboard systems involving minimal manning and optimized for operation in high seas in conjunction with education and training of undergraduate and graduate students in naval engineering. The specific technical objectives of the effort were identified as: (i) development of innovative design of ships and mission effect surface crafts, (ii) development of design algorithms for hydrodynamic analysis and dynamic control systems, (iii) predictive tools for propulsion, and (iv) the development of on-line and web-based tools for research and education.

The FAU consortium has included UC Berkeley, who have been developing prediction tools for the hydrodynamic performance of different hull forms, and UT Austin, who have developed predictive tools for the design and matching of propulsion systems. FAU maintains close collaboration with the Center for Innovative Ship Design, NSWC-CD (CISD) in directing senior student design projects and through internship participation.

The education and training activities associated with the program, specific to ship design and naval engineering, has involved (i) assignment of pertinent senior design projects requiring designing, building and testing of ship systems, (ii) summer internships at CISD and related industry that provide practical training and motivation in support of the NNRNE program, (iii) graduate courses, theses and dissertations, (iv) program enhancements, (v) outreach to high school and undergraduate students, (vi) career placement upon graduation. These activities are conducted in collaboration with CISD personnel. The 10-week summer internships at CISD really motivate students in the program. The impact of these activities on ocean engineering education is assessed. At FAU, 23\% of graduates participating ocean engineering graduates over three years took up careers in Navy laboratories and ship related marine industry. Overall, 17\% of all students interning at CISD over five years took up jobs at Navy laboratories. 


\section{Introduction}

National Naval Responsibility for Naval Engineers (NNRNE) program was established by the Office of Naval Research (ONR) in 2001 to help assure the future US capability to develop creative and innovative ship designers and designs to effectively meet defense needs and commercial market opportunities. The initiative recognized that universities, government, shipbuilding industry, and professional societies are important components of current and future naval engineering profession. There is a need to combine best ideas and expertise residing in these components to excite, recruit and train high caliber students in the field, to develop competent naval engineers, to foster a creative environment for new research, engineering, and design tools opportunities, and to encourage innovation in ship design. The universities have a need to sustain an adequate research expertise, through working on long-term problems of importance to the Navy, so that an adequate pipeline of new researchers, engineers, and faculty exists to meet anticipated future needs and opportunities. Seven key science and technology (S\&T) emphasis areas for the program were identified: ship design tools, ship structural materials, hydromechanics, advanced hull designs, ship propulsion, ship automation, and systems integration.

Following a workshop in 2002, several university consortia, consisting of teams of complementary universities were formed under an ONR BAA to work with the newly formed Center for Innovative Ship Design, NSWC-CD (CISD) (see for example, Keane et al. ${ }^{1}$ ). The FAU Consortium consisted of Florida Atlantic University, University of California (UC), Berkeley, and University of Texas (UT), Austin. It chose to focus its effort on hull design and shipboard automation for future 'mission effective' Navy support ships that would be categorized as fast, responsive and automated. The chosen areas of emphasis have been (1) seakeeping, (2) dynamic stability, (3) drag reduction and propulsion, and (4) shipboard automation and control. The goal of the program has been the development of conceptual designs of Support Ship for Unmanned Vehicles (SSUV), optimized to sustain all types of unmanned operations. The specific technical objectives of the effort have been the development of: (i) innovative design of ships and mission effect surface crafts, (ii) design tools for hydrodynamic analysis and dynamic control systems, (iii) predictive tools for propulsion, and (iv) on-line and web-based tools for research and education. Particular thrust of the program has been to educate and train students who will make up the next generation of naval engineers and to foster the development of novel uninhibited ideas.

\section{NNRNE Program Effort}

In keeping with the goals of the NNRNE program, the FAU Consortium has had two broad components, 1) education and training and 2) development of design tools and algorithms for ships and ship systems. The specific elements of the approach undertaken by the Consortium in meeting the objectives of the program have been:

- Development of tools and algorithms for design of high performance ships and ship systems.

- Integration of research and education programs 
- Summer internships for graduating seniors and rising seniors at NAVSEA, CISD, and naval industry, working on implementation of practical designs on future Navy crafts and ship systems.

- Involvement of CISD personnel in selection and progress review of certain undergraduate senior design projects with the aim of bringing appropriate relevance to the projects. CISD involvement also serves to provide a recruiting conduit for Navy laboratories and the ship industry. The NNRNE program also facilitated funding of the projects.

- Faculty direction of MS and PhD research of graduates in identified areas of interest, with the aim of developing design tools and control systems for ship systems. At FAU, the graduate students involved have principally been students returning from internships described above, in an effort to provide a seamless link between senior design projects, practical naval industry internship, and graduate theses; this extended-period training process significantly enhances the quality of the student's education and the relevance of the research to the Navy needs. At UC, Berkeley and UT, Austin, the program emphasis has been on the development of design tools that can be accessed on-line through the web and that are respectively directed at performance of single and multiple hulls and at the development of improved propulsion systems.

- FAU/UT/UCB Faculty / CISD personnel campus visits and seminar programs

Specific emphasis of the program has evolved to reflect the thrust at CISD. For example, for 2004 - 06, ship systems specific to development of the Seabasing concept and associated technologies were considered. The Seabase is envisioned as a collection of mobile Navy ships at sea conducting operations that enable forces to mobilize ashore without a large logistics footprint. A Seabase has strategic advantages that include unconstrained maneuvering and reconfiguration, scalability to match operations, rapid deployment, reduced vulnerability to attack, local force projection, and no dependence on foreign governments for deployment. However, many of the enabling technologies for Seabasing do not exist, pointing to the need for new concepts and technologies to project a host of new capabilities from the sea. Science and technology efforts in several areas are required, including, but not limited to: efficient at-sea skin-to-skin transfers from small to large vessels in high sea states, intra-theater high-rate sealifts, improved vertical delivery methods, dynamic positioning in high sea-states, innovative reduced-weight hull design, increased power density, high speed force closure using ships utilizing waterjet propulsion and skin-friction drag reduction techniques, and automated cargo handling for reduced manning. The diversity of S\&T requirements undoubtedly provides a rich multitude of exciting opportunities for faculty research and student development.

\subsection{Institutional Partners of the NNRNE Consortium}

Florida Atlantic University, University of California, Berkeley and University of Texas, Austin together represent a complementary team, both geographically and in terms of available facilities and expertise. Consortium effort has been based on leveraging existing strengths of the partner institutions in ocean engineering and naval architecture in a manner that not only benefits student education, but also enhances the respective programs of the institutions. The NNRNE program has resulted in collaborative efforts between the partners. The strengths of the institutions are described below. 


\subsubsection{Florida Atlantic University}

The Department of Ocean Engineering at Florida Atlantic University was founded in 1965, following the loss of the loss of the Thresher, as the first ocean engineering undergraduate program in the nation. Since then, it has grown significantly in terms of students, faculty, undergraduate and graduate programs, faculty research and departmental resources. As a result, the Department has 14 faculty members, 11 full-time engineers and technicians, two postdoctoral researchers, together with 180 undergraduate and 60 graduate students. The Department now spans two campuses, the Boca Campus where it originated and the new Dania Beach Campus which houses SeaTech, FAU's Institute for Ocean and Systems Engineering. The graduate program and the research activities are significantly focused at SeaTech. The undergraduate program is primarily based at the Boca Campus, but the students spend their senior year at SeaTech where they benefit from SeaTech facilities, participation in faculty research and building a rapport with a diverse graduate student body and practicing engineers. In 1974, the FAU Ocean Engineering Program was designated a "State University Program of Distinction" by the Florida Board of Regents. To date, the program has graduated over 1600 engineers, including over 200 women. Graduates of the Department are employed in offshore industry, various Navy laboratories and small design and ocean technology development companies. The Department's team of faculty, engineers and graduate students are engaged in federally and industry sponsored ocean engineering research and technology development in the areas of acoustics, marine vehicles, hydrodynamics and physical oceanography, marine materials nano-composites, applied ocean systems and ocean energy. A recent grant from the State has resulted in the development of a center of excellence in ocean energy technology at FAU, based on harnessing energy from the Gulf Stream. SeaTech builds on and complements the academic programs of the Department of Ocean Engineering and forms the means for technology advancement, collaboration with academia, industry, and government, and transition of research products to applications.

\subsubsection{University of California, Berkeley}

At UC, Berkeley, the ocean engineering program is an interdisciplinary group within the College of Engineering with its own admission quota and degree requirements. Marine-Transportation Systems is one of three main thrusts of the program, the others being Offshore Energy and Coastal Processes. Ship design and ship engineering issues are addressed at both undergraduate level, as a Naval Architecture Option in Mechanical Engineering, and at the graduate level (ship resistance, ship motion, free-surface flow methodologies, marine structures). In the Computational Marine Mechanics Laboratory at UC, Berkeley, mathematical and computational models are developed to describe and predict flows and hydrodynamic loads in many oceanengineering applications: e.g., ships, offshore structures, renewable energy extraction. The CMML is a fully networked facility with a bank of high-speed workstations and PCs. The laboratory at Richmond Field Station consists of a water basin $68 \mathrm{~m}$ long, $2.6 \mathrm{~m}$ wide and $2 \mathrm{~m}$ deep. Physical models are tested in the basin in simulated wave environment of the proper scales. The facility has both low-speed and high-speed tow carriages, a computer-controlled wavemaker, and a hydraulic oscillator. Instrumentation capabilities include some of the latest techniques, such as systems for laser fluorescence imagery and digital-particle image

velocimetry. Professor Yeung has graduated a large number of $\mathrm{MS}$ and $\mathrm{PhD}$ students in the area 
of Naval Architecture, Ocean Engineering, and Ship Hydrodynamics. Enrollment in the undergraduate Naval Architecture-Ocean Engineering Option course work is about 10 per year. The Graduate Program yields about 10 students per year, of which 4 are directly associated with the US Navy through the Naval Academy or equivalent training. Another 6 additional students per year from Mechanical Engineering and Civil Engineering also attend courses through crossdisciplinary interests. Starting from Fall 2006, the Ocean Engineering Graduate Group was administratively organized as a Major Field of Study within Mechanical Engineering.

\subsubsection{University of Texas, Austin}

The Ocean Engineering Group at UT, Austin is part of Civil Engineering. Typically the group has 6-8 graduate students. In addition, there is the Offshore Technology Research Center (joint with TAMU) with activities in the general areas of fluid/structure interaction, materials, and seafloor engineering, with emphasis on deep-water offshore structures (with a total of 10-15 graduate students). At the undergraduate level, there is a senior level course in Ocean Engineering, which is typically attended by over 30 students per year. The current projects in the area of hydrodynamics include marine propulsors, dynamic response of spars and floating production systems for storage and off-loading (FPSOs), and vortex induced vibrations of spars, risers, or other components of offshore structures.

Within the consortium, the FAU effort has primarily been focused on seakeeping and shipboard automation, that of the UC Berkeley on the development of prediction tools for the hydrodynamic performance of different hull forms, particularly multi-hull systems, and that of the UT Austin on the development of predictive tools for the design and matching of propulsion systems. FAU has maintained close collaboration with CISD in directing senior student design projects and through internship participation. Industry involvement in the internship program has included Lockheed Martin.

Interaction between faculty, students, institutional partners, and CISD has been through:

- Weekly progress meetings between faculty advisors and graduate students

- Bi-weekly review of progress on senior design projects between seniors and faculty instructors

- Monthly progress and strategy conference call meetings between institutional partners

- Periodically, face-to-face meetings were held between institutional partners at SeaTech, FAU.

- Once per year, in November - December timeframe, a critical design review of senior design projects have been held where CISD and industry personnel have been invited to provide comments.

- Once per year, CISD personnel have been invited to make a presentation of the internship activities at CISD.

- During fall semester, students are encouraged to participate in the NNRNE supported internship program. 


\section{Impact on Ocean Engineering Education and Training}

The NNRNE program has helped to a) enhance the education and training in ocean and naval engineering offered by the FAU-Consortium Institutions through collaborations between the institutions and through student interactions with CISD whereby they gain vital practical experience in ship design, and b) provide students with career paths in naval engineering in industry and government. The impact can be assessed in terms of the following five areas: 1) capstone design projects for undergraduate seniors, 2) summer internships for undergraduates, 3 ) graduate education, 4) outreach to high school and undergraduate students, 5) specific program enhancements, and 5) career placement efforts.

\subsection{Capstone Design Projects for Undergraduate Seniors}

As part of the undergraduate ocean engineering program at FAU, senior year students take a two semester capstone design course where they are tasked with designing an operational system that they take from concept development through engineering design, through building of the system to at-sea testing. The projects are group activities involving teams of students who are tasked to produce a design that meets a set of pre-specified metrics. The senior design experience has been enhanced as part of the NNRNE program through the participation of CISD personnel, through the provision of funding for the projects, thereby facilitating consideration of more ambitious projects. In alignment with the NNRNE goals, the FAU Ocean Engineering senior design class aims to familiarize students with marine and ship state-of-the art technology and design tools and to involve students in research and development of new ship innovations and design tools and algorithms focused on satisfying the navy technology needs.

Recent projects have included design and construction of scale models (Figure 1) of (i) a highspeed twin-hull craft and a novel hull concept with water jet propulsion in 2002-03, (ii) an underway launch and recovery system and a PHIN HYSWAS ship in 2003-04, (iii) a Deep Water Stable Craneship (DWSC) and a system for harnessing ocean current energy in 2004-05, (iv) a Dynamic Positioning System for a scaled model of a LMSR in 2005-06, and (v) a multiuse float-on float-off (MUFF) ship. The high-speed vessel was used to model the dynamics and control of the full-scale twin-hull support ship. The HYSWAS craft is an alternative hull form capable of moderately high speeds and excellent seakeeping. The hull form is characterized by a lower body of revolution, a large vertical strut, and a superstructure. The DWSC involved construction of a 1/12th scale model and has led to a grant from ONR for development of a rapidly deployable stable prototype platform.

\subsection{Summer Internships for Undergraduates}

Rising seniors and graduating seniors at FAU have participated in the 10-week summer internships at CISD through the NREIP program whereby the students receive stipends. As part of the NNRNE effort, FAU has been able to provide lodging support to students during their stay at CISD. At CISD, students work in innovation cells to brainstorm concepts and determine a preliminary design. The effort involves ${ }^{2}$ : 
- Focused, high-intensity projects

- Teams with government, academia and industry members

- Exploring ship design capabilities/needs for specific product lines

- Educational and professional development opportunities

- Emphasizing intern/mentor relationships

Mentors assigned to the projects supervise students as needed and monitor progress which includes a mid-term project review. During the internship, the students interact with students from other schools and are exposed to a number of design tools that significantly enhances their hands-on education. In particular, participating students have undergone training in the use of various industry-based software including one or more of the following: Advanced Surface Ship Evaluation Tool (ASSET), Ship Motion Program (SMP), Seaway Evaluation Program (SEP), Rhinoceros 3D Modeling Program, Bryce 3D Animation Program. Further, the students are required to write a technical report and make a presentation before a mixed audience consisting of experts and non-experts at the end of the internship. Some works have resulted in subsequent presentations at peer-reviewed conferences (see e.g., Venezia et $\mathrm{al}^{3}$ ). Collectively, the internship experience clearly has a positive impact on their education. Students returning from the internship show measurable enthusiasm and excitement, speaking highly of their experiences.

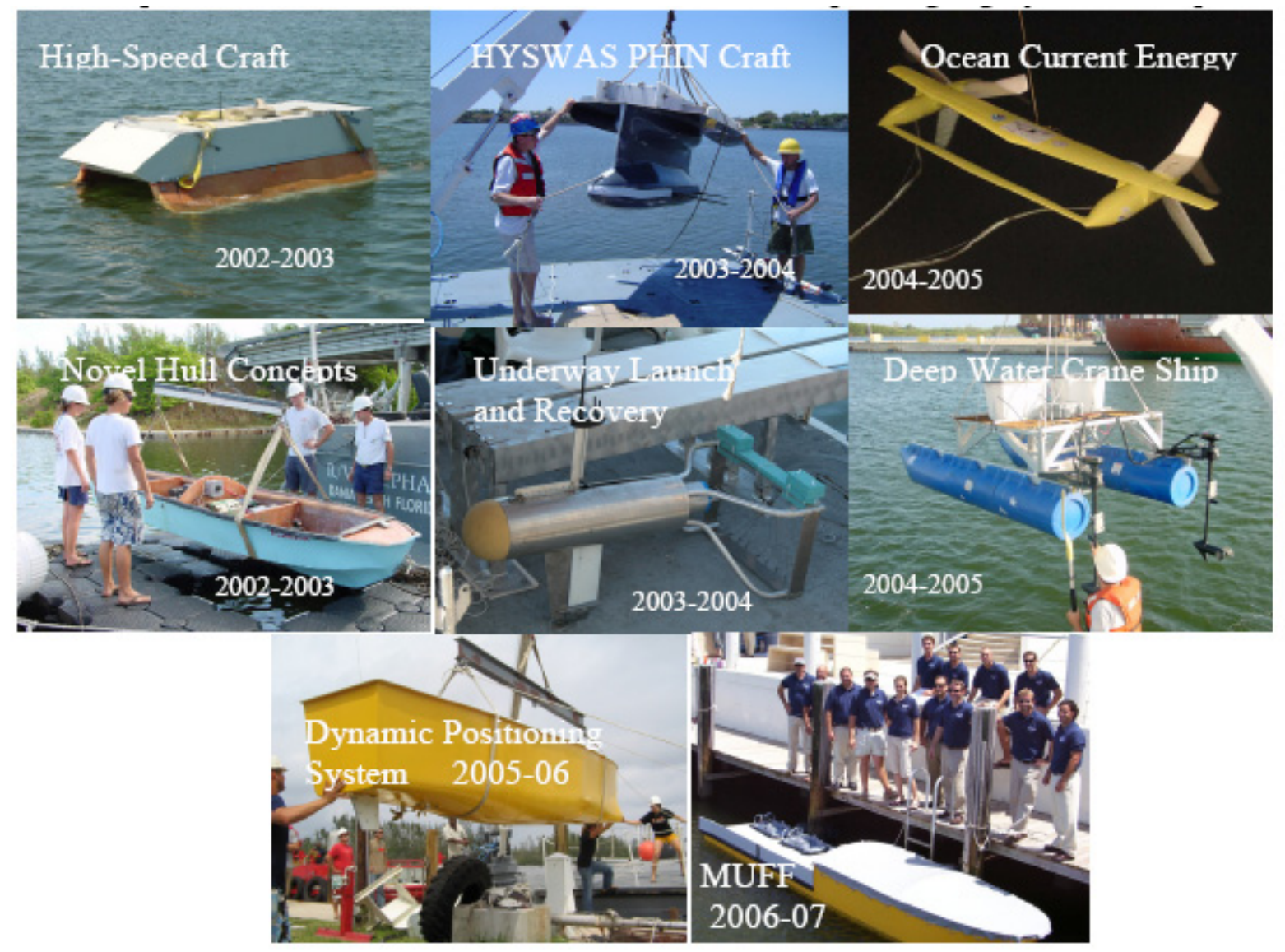

Figure 1 Senior Design Projects at FAU 2003-07.

The number of FAU students that took part in summer internships at CISD / Lockheed Martin Perry Technologies and others during 2003-05 was as follows: 
2003:

- 5 US students (2 Juniors / 3 Seniors / 1 female / 1 minority) to NSWC-CD

- 2 joined MS program at FAU/OE; 1 joined NSWC-PC, 1 joined NSWC-CD

- 1 student won DOD PhD award

2004:

- 5 US students (2 Juniors / 3 Seniors / 2 female) to CISD / NAVSEA

- 4 US students (2 Juniors / 2 Seniors / 2 female / 1 minority) to Lockheed Martin-Perry Technologies

- 4 joined MS program at FAU/OE (1 female)

2005:

- 2 US students ( 1 junior (female) / 1 senior) to CISD

- 1 US student (senior) to Lockheed Martin-Perry Technologies

- 2 US students working on completing DWSC project

- 2 US student (1 junior (female) / 1 senior) to Perry- Slingsby

2006:

- 4 joined MS program at FAU/OE (1 female)

- 4 US students (2 junior (1minority) / 2 senior) to CISD

- 1 US student (junior) to Lockheed Martin-Perry Technologies

- 2 US students working on completing DWSC project

- 2 US students (junior (1 female)) to SPAWAR

2007:

- 8 joined MS program at FAU/OE ( 3 female)

- 2 US students participated at CISD

- 1 US student to Lockheed Martin-Perry Technologies

2008:

- 8 US students participated at CISD, NSWC-CD

- 1 US student to NUWC, Newport, RI

- 1 US student participated Lockheed Martin-Perry Technologies

- 8 Other

These students participated in a number of design projects at CISD and in real-life design situation (see e.g. Peters and Kennell ${ }^{4}$ ) on a number of design problems, including an Intermediate Transfer Station, a Deep Water Stable Craneship, a hover barge, TIES ASSET evaluations for a LCS, and Project MOSES.

\subsubsection{Graduate Education}

On completion of their internships, some of the students return as graduate students to work on thesis and dissertation topics pertinent to the development of tools and algorithms for design of ships and ship systems. Over $2003-2008$, several graduate students working in the areas of seakeeping and ship stability, automation and control, and drag reduction and propulsion have been supported by the program at each of the three partner institutions. The project areas for MS theses and $\mathrm{PhD}$ dissertations have included: 
- Determination of hydrodynamic coefficients of multi-hull ships for seakeeping analysis (FAU)

- Dynamic Stability of Fast Ships (FAU)

- Skin Friction Reduction Using Microbubbles (FAU)

- Boundary layer control on a circular cylindrical body through oscillating Lorentz forcing (FAU)

- Predictive DP Utilizing Inertial and Environmental Measurements (FAU)

- Dynamic Stationary and Underway Positioning of Underactuated Vessels (FAU)

- Automatic Station Keeping of Small Twin Screw Boats (FAU)

- High Rate "Pick and Place" Cargo Transfer between Vessels in High Sea States (FAU)

- Generic Simulation of Small and Medium Sized Vessels (FAU)

- Dynamic Positioning of a Large Spar Buoy Crane Ship (FAU)

- Advanced Position Control System for Multiple Vessels (FAU)

- Prediction of Performance and Design of Various High-Speed Marine Propulsion Configurations (UT, Austin)

- Multi-hull radiation hydrodynamic coefficients (UC, Berkeley)

- Configuration for Optimizing Multi-Hull Wave Drag (UC, Berkeley)

- Hydrodynamic Modeling for Design of Fast Multi-hulls (UC, Berkeley)

- Motion Predictor of Multi-Hulls (UC, Berkeley)

- High-Performance Hulls with Pressure Cushions and in Littoral Regions (UC, Berkeley)

The FAU Consortium effort is based on a multi-disciplinary approach that draws from several areas of program emphasis. Focus research areas have had good graduate participation at both Ph.D. and MS levels.

\subsubsection{Program Enhancements}

The NNRNE effort has resulted in a new MS track in Ship Design at FAU composed of a selection of a set of existing graduate courses encompassing hydromechanics, structures, advanced mathematics, oceanography and a specific course in ship design. A faculty member from the Naval Architecture program of the National Technical University of Athens has joined the program and new ties are being developed with Greek schools that have strong naval architecture / marine engineering programs to attract graduate students from these institutions.

At UT, Austin, NNRNE work has broadened the scope of work currently underway and has significantly increased exposure of students to real life applications. The students associated with the program have become familiarized with the state-of-the-art design technologies, and contribute by designing or assessing several high-speed hull and propulsor configurations of the future. The students in the Ocean Engineering Group, and the Offshore Technology Research Center in general, have also benefitted from being exposed to high-speed hull technologies through inclusion in currently offered courses topics being developed under the NNRNE effort.

At UC, Berkeley, the tools created under the NNRNE program serve to enhance the education and training of undergraduate and graduate students in the Ocean Engineering Group. The analysis capabilities developed for ship-configuration design optimization ${ }^{5}$ was designed to allow internet-based access. They have significantly increased undergraduate interest in ocean- 
engineering courses in UC, Berkeley. Eight other universities and commercial entities also requested were granted access to the web-based design tools ${ }^{6}$. The multi-hull configuration design tool can handle up to a maximum of five hulls.

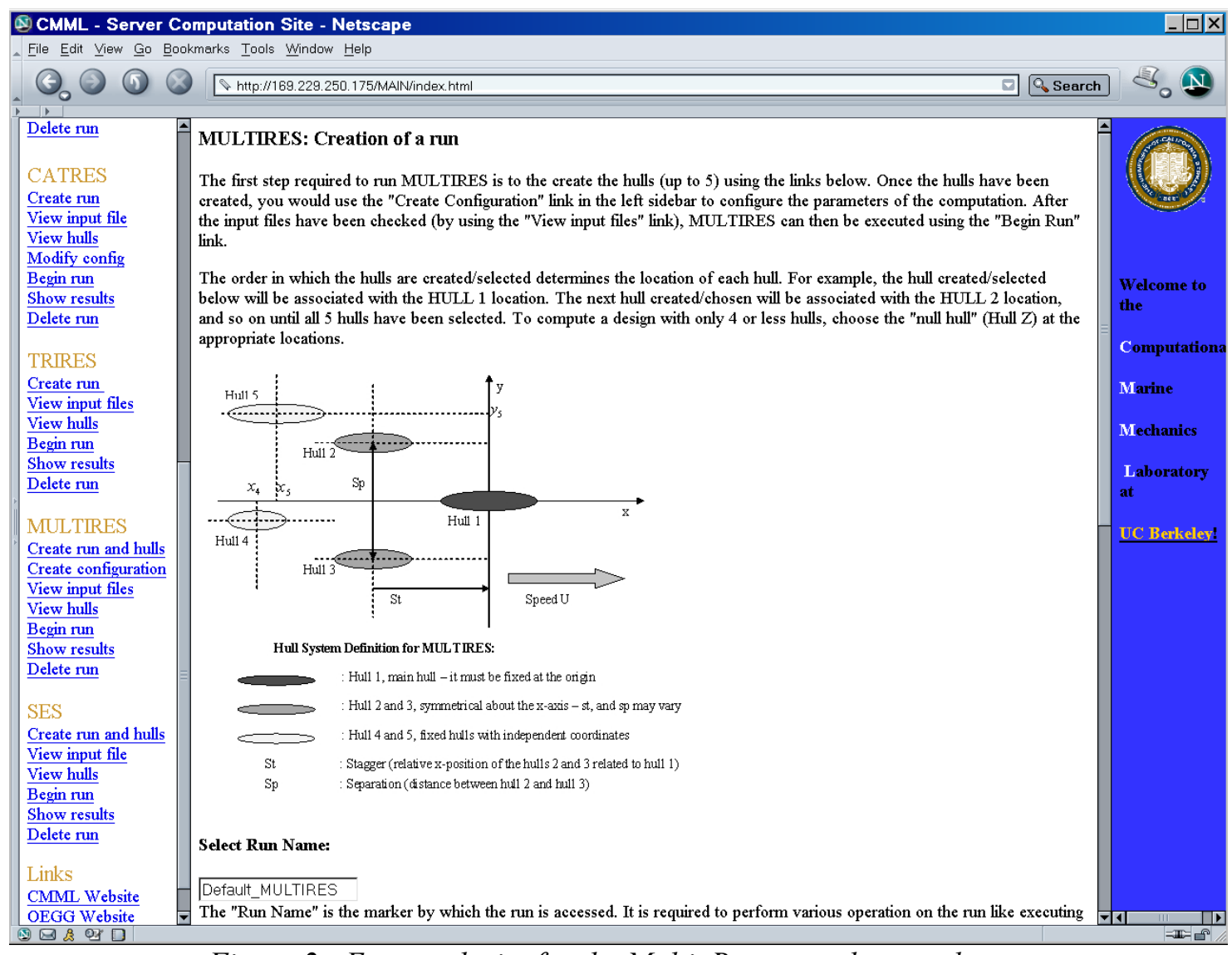

Figure 2: Entry web site for the Multi_Res wave-drag evaluator

\subsubsection{Outreach to High School and Undergraduate Students}

The NNRNE program has supported the Sea Perch program through SNAME. This has helped to generate exciting projects for FAU's outreach activities and has lead to development of other projects such as a mechanically powered submarine, an autonomous surface vehicle and energy harnessing devices. The outreach activities at FAU aimed at high school and undergraduate students include:

- Submarine Workshop for High School Students

- $9^{\text {th }}-10^{\text {th }}$ graders, working in groups, design, build, test and race their submarines (23 students in 2004; 8 in 2005).

- Summer Dual Credit Earning Class in Ocean Engineering for $10^{\text {th }}-12^{\text {th }}$ graders with high GPAs,

- Based around Sea Perch ${ }^{7}$ and Marine Operations; (24 students in 2004;

24 students in 2005; 27 students in 2006, 24 students in 2007 and 2008)

- REU Program (NSF / DOD Funded) 
- Undergraduate students from around the country participate in research projects during summer (9 students in 2004; 8 in 2005)

The REU is a 10-week summer program sponsored by the National Science Foundation (NSF) and the Department of Defense (DoD). It provides research experience for academically-talented undergraduates who may have limited opportunities for Ocean Engineering research at their home institutions. There is a special interest in attracting students who are from minority groups that are under-represented in engineering. The main goals of the program are to draw and retain high-quality US students to careers in science and engineering, with a focus on attracting the students to ocean and naval engineering.

\subsubsection{Career Placement}

The NNRNE program provides students with opportunities to interact directly with NSWC-CD, other government laboratories and industry, through the summer internships and personal contact with personnel from these organizations. As a result, motivated students are better prepared for seeking careers in ship design and naval engineering. Over 2003-05, out of 47 graduating FAU students, 11 took jobs in naval engineering /ship design in government labs and industry, including 3 at NSWC, and 17 have enrolled for graduate studies. CISD reports ${ }^{2}$ that of the 113 students who interned at CISD between 2003 and 2007, 19 accepted jobs within NAVSEA/NSWCCD/Naval ship yard.

\section{Development of Design Tools and Enhancement of Faculty Research}

The NNRNE effort has resulted in the development of algorithms and tools for design and development of ships and ship systems. A number of research publications have resulted and faculty development has been enhanced. The specific accomplishments may be summarized as follows:

\section{At FAU:}

- Algorithms for multi-hull ship stability and maneuverability

- Algorithm for dynamic positioning of "small" underactuated vessels

- General dynamic simulation of small and medium-sized displacement surface craft

- Stability, maneuverability and motion response of multi-hull ships.

- Algorithm for studying characteristics of drag reduction using Lorentz force in a boundary layer.

\section{At UC, Berkeley:}

- Web-based computational tools for evaluating transverse-motion radiation properties of ship hull sections, including non-linear viscous damping and keel bilge effects.

- A fast web-based design tool for evaluating wave-drag interference for $\mathrm{N}$ hull systems. The computational tools TRIRES (Tri-hull) and MULTIRES now has any-time anywhere internet access. 
- Improvements and validations of tools for prediction of the performance of open, ducted, or podded propellers, subject to general nonaxisymmetric inflow

- Development of UT tool (CAVOPT-BASE) for the design of propulsor blades

At FAU the effort has been based on autonomous and semi-autonomous control strategies and on hydromechanics of multi-hull ships, pertinent to the Seabasing concept. The developments have been based on theses and dissertation projects described in 3.2.1. The work has resulted in simulation tools for dynamic positioning and other control and automation aspects of ship design and computational algorithms to determine hydrodynamic coefficients of multi-hull ships which are traditionally determined in a model basin.

At UC, Berkeley, the efforts consisted of developing solution for ship hydrodynamic issues pertinent to preliminary multi-hull design and to possible integration into education and industry use. A robust web-based computational tool, TRIRES, has resulted and now has any-time anywhere internet access by multiple institutions.

At UT, Austin, tools have been developed on the prediction of performance of open, ducted, and podded propulsors, based on an iterative approach between a finite volume method for the analysis of the global flow, and a lifting surface method for the modeling of the flow (including the effects of sheet cavitation) around propulsor blades, including the design of open or ducted propeller blades.

\section{Conclusions}

It is clear that the NNRNE program has had a significantly positive impact on the ocean engineering education at FAU and on the respective programs of the three partner institutions of the FAU Consortium. It has enhanced the quality of the senior design projects undertaken by students at FAU, fostered meaningful internships at CISD, thereby benefitting the professional development of students, provided thesis and dissertation development opportunities to graduate students at the three institutions, and improved outreach efforts at FAU. The NNRNE program has created an important conduit for recruitment of naval engineers. The three institutions have developed a good working relationship. The program has led to inter-institutional faculty visits and seminar presentations. These visits have been enriching for the students and for the faculty in development of new design tools. The tools developed at UC, Berkeley and at UT, Austin have been utilized by senior design students at FAU in pursuing their projects. One of the graduate students from FAU, on completion of his MS Degree has gone to UT, Austin to pursue a PhD. Other inter-institution collaborative proposals have been submitted. The scope of the faculty research at the three institutions has been broadened and is leading to new opportunities. One of the senior design projects at FAU led to an ONR grant on development of a Seabase enabling technology in collaboration with industry. This in turn has resulted in the development of new industry ties that are expected to provide value-added benefits. 


\section{Acknowledgements}

The program has been supported by the Office of Naval Research under grant N000140310211 (Program Manager: Ms. Kelly Cooper). We thank the graduate students at the three institutions and the FAU undergraduate student interns who participated in the program. We acknowledge the participation and contributions of Dr. P. Ananthakrishnan, Dr. Joe Cuschieri, Dr. Rick Driscoll, and Dr. Dave Vendittis. The program is indebted to the CISD personnel and individuals visiting CISD, including Steve Ouimette, Dr. Jeffery Hough, Dr. Colen Kennel, Mark Selfridge, Cmdr. Russell Peters, and Chris Dicks.

\section{References}

1. Keane, Robert G., Fireman, Howard, Billingsley, Daniel W., 2007. "Leading a Sea Change in Naval Ship Design: Toward Collaborative Product Development" Journal of Ship Production, Vol. 23, 53-71.

2. Ouimette, Steven Center for Innovation in Ship Design (CISD): “An Overview. 2007 National Naval Engineering Education Conference". NSWC-CD, 2007.

3. Venezia, Anthony, Glenn Tucker, Jacqueline Beitel, Greg Kemble, Andy Pugh, Larry Snyder, Sam Morgante. “Application of Heavy Lift Ship Technology as a Seabasing Enabler”, Paper, MTS Oceans '04. IEEE. Kobe, Japan, November 2004.

4. Peters, Russell CF LCDR, Kennell, Colen, 2005 "Use of Seaplanes and Integration within a Sea Base" ASNE Seabasing Conference, Arlington, VA.

5. Yeung, Ronald W., Poupard, Gregoire, and Toilliez, Jean O., "Interference-Resistance Prediction and Its Applications to Optimal Multi-Hull Configuration Design", Transactions of the Society of Naval Architects \& Marine Engineers, vol. 112, pp. 142-169, 2004.

6. Yeung, Ronald. W. and Wan, Hui, "Multi-Hull and Surface-Effect Ship Configuration Design - A Framework for Powering Minimization," ASME-Journal of Offshore Mechanics and Arctic Engineering, Vol. 130, No. 3, 2008, http://link.aip.org/link/?JOM/130/03/031005/1.

7. Michetti, Stephen, Givers, Susan. "The Sea Perch Challenge - Generating Interest in Marine Engineering, Ocean Engineering, Naval Engineering and Naval Architecture through hands-on activities" 2008. ASEE Annual Conference \& Exposition. http://soa.asee.org/paper/conference/paper-view.cfm?id=7464 